\title{
EUS-Guided Biliary Drainage
}

Kenji Yamao*, Kazuo Hara*, Nobumasa Mizuno*, Akira Sawaki*, Susumu Hijioka*, Yasumasa Niwa ${ }^{\dagger}$, Masahiro Tajika ${ }^{\dagger}$, Hiroki Kawai ${ }^{\dagger}$, Shinya Kondo ${ }^{\dagger}$, Yasuhiro Shimizu ${ }^{\ddagger}$, and Vikram Bhatia ${ }^{\S}$

Departments of ${ }^{*}$ Gastroenterology, ${ }^{\dagger}$ Endoscopy and ${ }^{\dagger}$ Gastrointestinal Surgery, Aichi Cancer Center Hospital, Nagoya, Japan, and ${ }^{\S}$ Department of Medical Hepatology, Institute of Liver and Biliary Sciences, Delhi, India

Endoscopic ultrasonography (EUS) combines endoscopy and intraluminal ultrasonography, and allows imaging with a high-frequency transducer over a short distance to generate high-resolution ultrasonographic images. EUS is now a widely accepted modality for diagnosing pancreatobiliary diseases. EUS-guided fineneedle aspiration (EUS-FNA) using a curved linear-array echoendoscope was initially described more than 20 years ago, and since then many researchers have expanded its indications to sample diverse lesions and have also used it for various therapeutic purposes. EUS-guided biliary drainage (EUS-BD) is one of the therapeutic procedures that has been developed using a curved linear-array echoendoscope. Technically, EUS-BD includes rendezvous techniques via transesophageal, transgastric, and transduodenal routes, EUS-guided choledochoduodenostomy (EUS-CDS), and EUS-guided hepaticogastrostomy (EUS-HGS). Published data have demonstrated a high success rate, albeit with a comparatively high rate of nonfatal complications for EUS-CDS and EUS-HGS, and a comparatively low success rate with a low complication rate for the rendezvous technique. At present, these procedures represent an alternative to surgery or percutaneous transhepatic biliary drainage (PTBD) for patients with obstructive jaundice when endoscopic biliary drainage (EBD) has failed. However, these procedures should be performed in centers with extensive experience in linear EUS and therapeutic biliary ERCP. Large prospective studies are needed in the near future to establish standardized EUS-BD procedures as well as to perform controlled comparative trials between EUS-BD and PTBD, between rendezvous techniques and direct-access techniques (EUS-CDS and EUS-HGS), and between EBD and EUS-BD. (Gut Liver 2010;4(Suppl. 1):S67-75)
Key Words: Endoscopic ultrasonography; Endoscopic ultrasonography-guided biliary drainage; Rendezvous technique; Endoscopic ultrasonography-guided choledochoduodenostomy, Endoscopic ultrasonography-guided hepaticogastrostomy

\section{INTRODUCTION}

Endoscopic ultrasonography (EUS) is a combination of endoscopy and intraluminal ultrasonography. It uses a high frequency transducer of $5 \mathrm{MHz}$ to $10 \mathrm{MHz}$. Due to the short imaging distance to the target lesion, EUS enables ultrasonographic images of high resolution to be obtained. EUS is now a widely accepted modality for the diagnosis of gastrointestinal and pancreatobiliary diseases. In 1992, Vilmann et al. ${ }^{1}$ published the first case report of EUS-guided fine needle aspiration (EUS-FNA) of a lesion in the pancreas head using a curved linear array echoendoscope. Since then, many researchers have expanded the indications for EUS-FNA to include various kinds of lesions, and also for therapeutic purposes. ${ }^{2}$

Endoscopic biliary drainage (EBD) is a well-established technique for providing biliary decompression in patients with bile duct obstruction. However, there are patients in whom EBD fails because of failed biliary cannulation, or inaccessible papilla due to duodenal stenosis caused by tumor invasion. In these cases percutaneous transhepatic biliary drainage (PTBD) or surgical intervention is required, although both these methods carry a higher morbidity and mortality.

EUS-guided cholangiography was first described by Wiersema et al. ${ }^{3}$ in 1996. Since then several variations of

\footnotetext{
Correspondence to: Kenji Yamao

Department of Gastroenterology, Aichi Cancer Center Hospital, 1-1 Kanokoden, Chikusa-Ku, Nagoya 464-8681, Japan

Tel: +81-052-762-6111, Fax: +81-052-763-5233, E-mail: kyamao@aichi-cc.jp
}

DOI: $10.5009 /$ gnl.2010.4.S1.S67 
EUS-guided biliary drainage (EUS-BD) have been reported as salvage techniques for failed EBD. ${ }^{4-27}$ In this review, we describe the techniques and present status of EUS-BD procedures.

\section{EUS-BD}

Wiersema et al. ${ }^{3}$ first described EUS-guided cholangiopancreatography in 1996 as a diagnostic alternative in two patients with failed ERCP. Recent reports have demonstrated the feasibility of EUS-guided cholangiography with biliary stent placement in patients with failed cannulation at ERCP. EUS-guided biliary drainage includes two methods: a rendezvous technique and a direct access technique, and two approach routes: transgastric approach and transduodenal approach.

\section{EUS-guided biliary drainage with a rendezvous technique}

EUS-guided bile duct drainage with a rendezvous technique was first described by Mallery et al. ${ }^{6}$ in 2004. Hereafter, other researchers have also reported EUS-BD using a rendezvous technique.

\section{1) Technique for EUS-BD with a rendezvous tech-} nique

(1) Once the echoendoscope is positioned in the esophagus, stomach, or duodenum, and the bile duct is visualized by endosonography, the bile ducts are punctured with a 19- or 22-gauge needle (Fig. 1A).
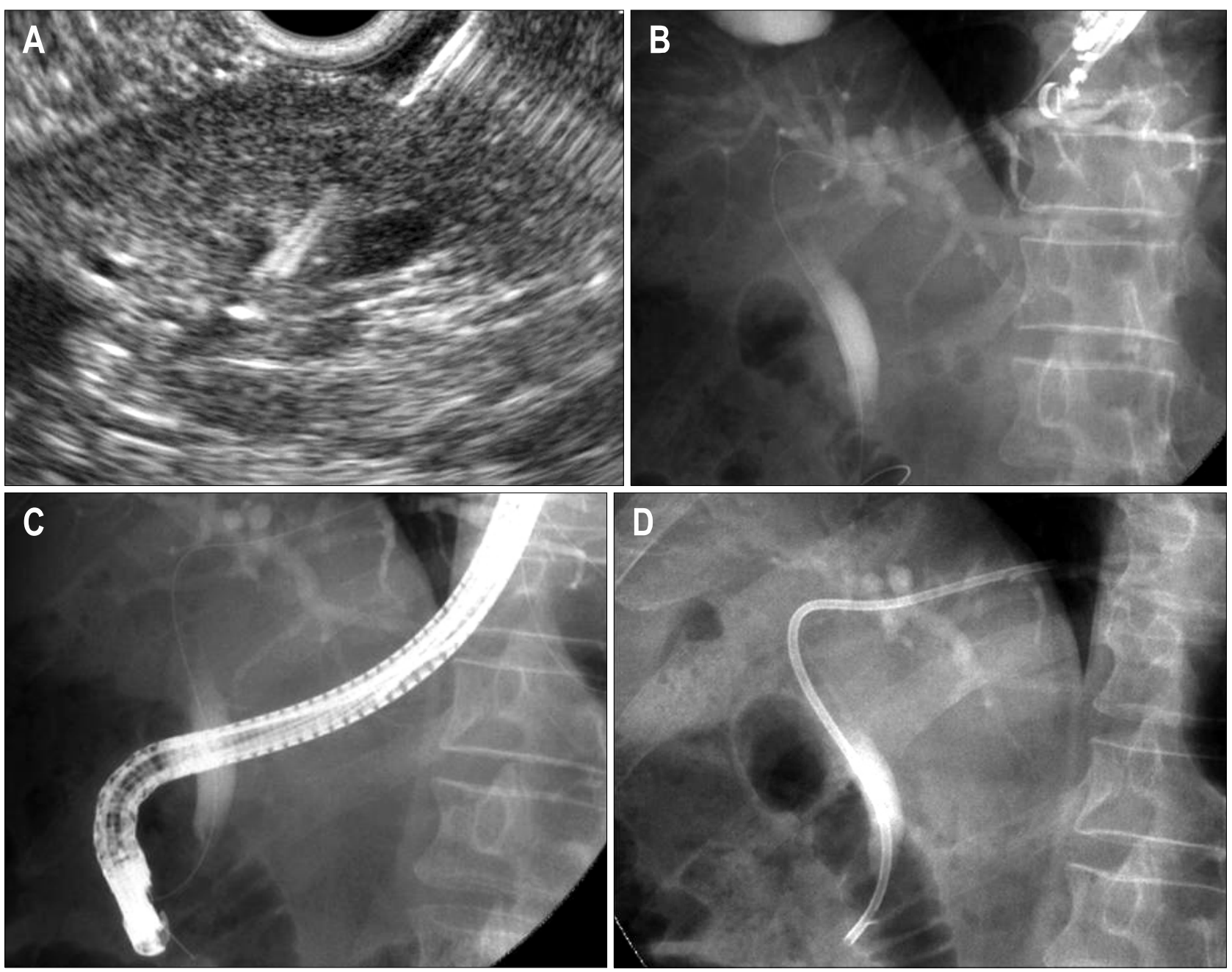

Fig. 1. Endoscopic ultrasonography-guided biliary drainage with a rendezvous technique. (A) After the echoendoscope was positioned in the esophagus and the slightly dilated intrahepatic bile ducts were visualized by endosonography, the bile ducts were punctured with a 19- or 22-gauge needle. (B) After successful intraductal bile duct puncture, a guide wire was advanced distally through the stricture and the papilla by fluoroscopy. (C) The guide wire was grasped with a snare and pulled back out the working channel of the duodenoscope for subsequent over-the-wire cannulation. (D) Endoscopic retrograde cholangiography with stent placement was achieved over the guide wire. 
Table 1. Overview in the Reported Cases with EUS-Guided Biliary Drainage with Rendezvous Method

\begin{tabular}{|c|c|c|c|c|c|c|c|}
\hline Authors & Year & $\begin{array}{l}\text { No. of } \\
\text { cases }\end{array}$ & $\begin{array}{l}\text { Device for } \\
\text { puncture }\end{array}$ & $\begin{array}{l}\text { Site of puncture } \\
\text { (No. of cases) }\end{array}$ & $\begin{array}{l}\text { Technical } \\
\text { success }\end{array}$ & $\begin{array}{l}\text { Initial stent } \\
\text { (No. of cases) }\end{array}$ & $\begin{array}{l}\text { Complication } \\
\text { (No. of cases) }\end{array}$ \\
\hline Mallery et al. & 2004 & 2 & $19 \mathrm{G} / 22 \mathrm{FN}$ & Duodenum (2) & $2 / 2(100 \%)$ & MS (2) & None \\
\hline Lai et al. & 2005 & 1 & 19G FN & Duodenum (1) & 1/1 (100\%) & CMS (2) & None \\
\hline Kahaleh et al. & $2004,05,06^{*}$ & 20 & $19 / 22 \mathrm{FN}$ & $\begin{array}{l}\text { Stomach (17), } \\
\text { duodenum (3) }\end{array}$ & $18 / 20(90 \%)$ & $\begin{array}{l}\text { 10F PS (8), } \\
\text { MS (10) }\end{array}$ & $\begin{array}{l}\text { Pneumoperitoneum (1), } \\
\text { bile leak (1) }\end{array}$ \\
\hline Will et al. & 2007.07 & 1 & $19 \mathrm{FN}$ & Esophagus (1) & $1 / 1 \quad(100 \%)$ & 8.5F PS (1) & None \\
\hline Tarantino et al. & 2008 & 8 & $19 / 22 \mathrm{FN}$ & Duodenum (8) & $4 / 8(50 \%)$ & PS (4) & None \\
\hline Kim et al. & 2009 & 15 & $19 / 22 \mathrm{FN}$ & $\begin{array}{l}\text { Duodenum (14), } \\
\text { stomach (1) }\end{array}$ & $12 / 15(80 \%)$ & $\begin{array}{l}\text { 10F PS (4), } 10 \mathrm{~mm} \\
\text { MS (6), CMS (2) }\end{array}$ & None \\
\hline Total & & 47 & & $\begin{array}{l}19 \text { duodenum, } \\
18 \text { stomach, } \\
1 \text { esophagus }\end{array}$ & $38 / 47(81)$ & & 2/47(4) \\
\hline
\end{tabular}

FN, fine needle; MS, metal stent; CMS, covered metal stent; PS, plastic stent.

${ }^{*}$ Excluding the overlapping cases.
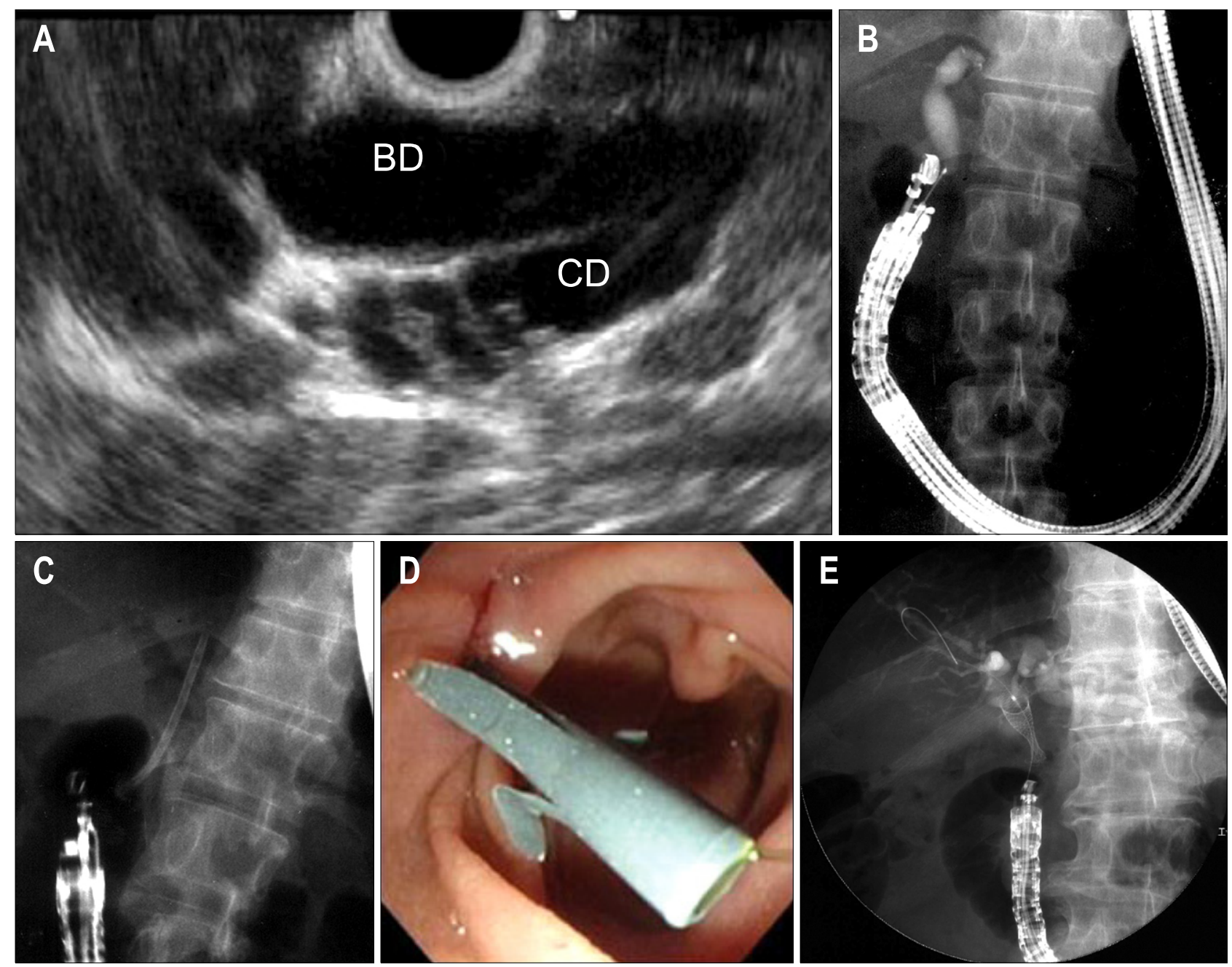

Fig. 2. Endoscopic ultrasonography-guided choledochoduodenostomy (EUS-CDS). (A) Convex echoendoscope, located in the apex of the duodenal bulb, clearly displayed the extrahepatic bile duct and cystic duct. (B) The echoendoscope was observed in the long/pushing scope position. Cholangiogram obtained by EUS-guided puncture with the tip of the convex transducer directed to the hepatic hilum. (C) Choledochoduodenostomy was accomplished using a plastic stent in the apex of the duodenal bulb. (D) The plastic stent was visible in the first portion of the duodenum. (E) The covered metal stent was also available for EUS-CDS. 
(2) Contrast is injected through the EUS needle to display the intrahepatic and extrahepatic bile ducts.

(3) After confirmation of successful bile duct puncture by endosonographic and fluoroscopic imaging, a guide wire (0.018-0.035 inch) is advanced distally through any stricture and across the papilla using fluoroscopic guidance (Fig. 1B).

(4) Once the guide wire has passed through the papilla into the duodenum, several loops of wire are made in the duodenum to stabilize the wire during subsequent endoscope exchange.

(5) The EUS scope is then removed leaving the guide wire in place.

(6) A duodenoscope is passed by the side of the EUS-placed guide wire up to the papilla.

(7) The papillary end of the guide wire is grasped with a snare or forceps and pulled back out the working channel of the duodenoscope for subsequent over-the-wire cannulation (Fig. 1C).

(8) Finally, access to the common bile duct is achieved and a standard endoscopic retrograde cholangiography (ERC) with stent placement can be performed (Fig. 1D).

\section{2) Review of articles (Table 1)}

Six reports ${ }^{6,8,9,14,20,23}$ on EUS-guided rendezvous technique have been published. Excluding overlapping cases in Mallery et al. $^{6}$ and Kim et $a .^{23}$, the rendezvous technique has been described in a total of 45 patients. Both 19 gauze and 22 gauze EUS-FNA needles have been used. The site of puncture included duodenum in 19 cases, stomach in 18 cases, and esophagus in 1 case. The overall success rate was $80 \%(36 / 45)$. The complication rate was $4 \%(2 / 45)$, including one each of pneumoperitoneum and bile leakage. Kim et al. ${ }^{23}$ reported moderately severe pancreatitis and bacteremia in each case as a complication, but not related to the EUS-guided rendezvous technique. According to the largest case series reported by Maranki et al. ${ }^{26}$, of the 49 patients who underwent the intrahepatic and extrahepatic approach only using EUS-guided rendezvous technique, the overall success rate of trans-papillary stenting was $65 \%(32 / 49)$.

A rendezvous technique is feasible only when the endoscope can be advanced to the papillary orifice or to the site of surgical anastomosis for retrieval of the guide wire. The EUS-rendezvous is used solely to puncture the obstructed bile duct and pass a guide wire antegradely through the native papilla to allow subsequent ERCP. ${ }^{23}$ Potential advantages of EUS-rendezvous access include achievement of biliary drainage at a single session by using conventional ERCP techniques, and possibly fewer complications than other EUS guided transluminal drain- age approaches. ${ }^{23}$ However, there are some cases where the guide wire cannot be advanced across the obstruction. In such situation, a duodenal-biliary fistula (a new papilla) created by precut and pneumatic dilation, ${ }^{20}$ conversion to PTBD, or a trans-enteric fistula and stent placement should be selected. ${ }^{26}$ Though the stent patency and late complications at long term follow-up of patients treated with this technique have not yet been reported in detail, those result seem to be basically the same as those of endoscopic trans-papillary biliary stent placement.

\section{EUS-guided choledochoduodenostomy (EUS-CDS)}

EUS-CDS was first reported by Giovannini et al. ${ }^{4}$ in 2001. The technique is basically similar to EUS-guided drainage of pancreatic pseudocysts. The technique of EUS-CDS, as performed in our hospital, is as follows. ${ }^{11,12,21,27}$

\section{1) Technique for EUS-guided choledochoduodeno- stomy}

(1) A convex-type ultrasound endoscope (GF-UCT240; Olympus Optical, Tokyo, Japan) is used, and the tip of the endoscope is placed in the duodenal bulb (Fig. 2A).

(2) Endoscopic observation is carried out to confirm the absence of any local lesion in the duodenal bulb.

(3) Long axis of the extrahepatic bile duct can be displayed from the duodenal bulb (Fig. 2B). At this stage, the position of the scope should be adjusted so that the direction of puncture is toward the hepatic hilum.

(4) The bile duct is punctured under EUS guidance using a 22-G FNA needle (NA-200H-8022; Olympus Optical) and bile is aspirated to confirm intra-ductal position of the needle tip.

(5) Contrast medium is injected through the needle to visualize the intra- and extrahepatic bile ducts.

(6) After removal of the needle, a needle knife (Zimmon papillotomy knife; Cook Endoscopy, WinstonSalem, NC, USA) is then inserted into the bile duct while setting the output current to the incision mode under real-time EUS guidance.

(7) The inner needle is removed, and a 0.35 -inch guidewire (length, $450 \mathrm{~cm}$, Jagwire; Microvasive Endoscopy, Boston Scientific, Natick, MA, USA) is inserted through the outer sheath deep into the intrahepatic bile duct.

(8) The outer cover of the needle knife is then removed, while and the intraductal position of the guide wire is maintained.

(9) The fistula (point of punctured) is dilated serially using tapered biliary dilation catheters of 6 Fr, 7 Fr, and 9 Fr in size (Soehendra biliary dilation catheters; Wilson-Cook), over the guide wire. 
(10) Finally, an 8.5-Fr straight biliary stent (Tannenbaum, Wilson-Cook or Flexma; Microvasive Endoscopy, Boston Scientific) is inserted through the choledochoduodenal fistula into the extrahepatic bile duct (Fig. 2C, D).

(11) The absence of intra-abdominal leakage of contrast medium should be confirmed on X-ray fluoroscopy.

\section{2) Modified technique of EUS-CDS}

(1) A 19-G needle (EchoTip; Wilson-Cook) is inserted trans-duodenally into the bile duct under EUS guidance.

(2) Bile is aspirated and contrast medium is injected into the bile duct for cholangiography.

(3) A 450-cm long, 0.035-inch guide wire is inserted into through the 19-G needle into the bile duct.

(4) The choledochoduodenal fistula is dilated using a biliary catheter for dilation (Soehendra biliary dilator; Wilson-Cook), or papillary balloon dilator (Maxpass; Olympus Medical Systems, Tokyo, Japan, or Hurricaine RX $4 \times 2$ 5.8/180; Microvasive Endoscopy, Boston Scientific). ${ }^{20}$

(5) A 5-Fr to 10-Fr biliary plastic stent or a covered self-expandable metallic stent (Fig. 2E) is placed through the choledochoduodenostomy site into the extrahepatic bile duct.

\section{3) Technique for exchanging an occluded EUS-} CDS stent (guidewire-assisted stent exchange) ${ }^{27}$

(1) A 0.035-inch guide wire is inserted into the bile duct through an occluded stent using an ERCP catheter when the stent has not been in situ for a long enough time for a mature choledochoduodenal fistula to have formed (Fig. 3A).

(2) The occluded stent is then removed using a snare with the guidewire in place, through the biopsy channel of the duodenoscope (Fig. 3B).

(3) A new 8.5-Fr straight biliary stent is inserted into the bile ducts over the guide wire.

\section{4) The simple technique for exchanging occluded stents in EUS-CDS}

The method for exchanging an occluded stent in our hospital is as follows.

(1) The occluded stent is removed using a dormia basket through a duodenoscope when the stent has been in situ for a sufficient period of time. The choledochoduodenal fistula is usually mature 2 or 3 weeks after stent insertion.

(2) After stent removal, an ERCP catheter (Tandem 3-lumen ERCP catheter; Microvasive Endoscopy, Boston Scientific) is inserted through the choledochoduodenal fistula into the bile ducts, followed by placement of a 0.035 -inch guidewire $(450 \mathrm{~cm}$, Jagwire; Microvasive Endoscopy, Boston Scientific) deep into the intrahepatic biliary ducts.

(3) A new 8.5-Fr straight biliary stent (Tannenbaum stent; Wilson-Cook) is inserted over the guide wire into the bile ducts.

\section{5) Review of published literature on EUS-CDS (Table 2)}

Thirteen studies including 33 patients have evaluated the role of EUS-CDS. ${ }^{4,5,10-13,15,16,20-22,24,25}$ A needle knife or fistulotome was used to access the bile duct in $17 \mathrm{pa}$ tients, EUS-FNA needles of 19 and $22 \mathrm{G}$ were used in 8 patients, and EUS-FNA needles of $19 \mathrm{G}$ and $22 \mathrm{G}$ followed by a needle knife in 8 patients. Although in 2 patients the procedure was unsuccessful, in the remaining $32 \mathrm{pa}$ tients (94\%) transduodenal stents were successfully in-
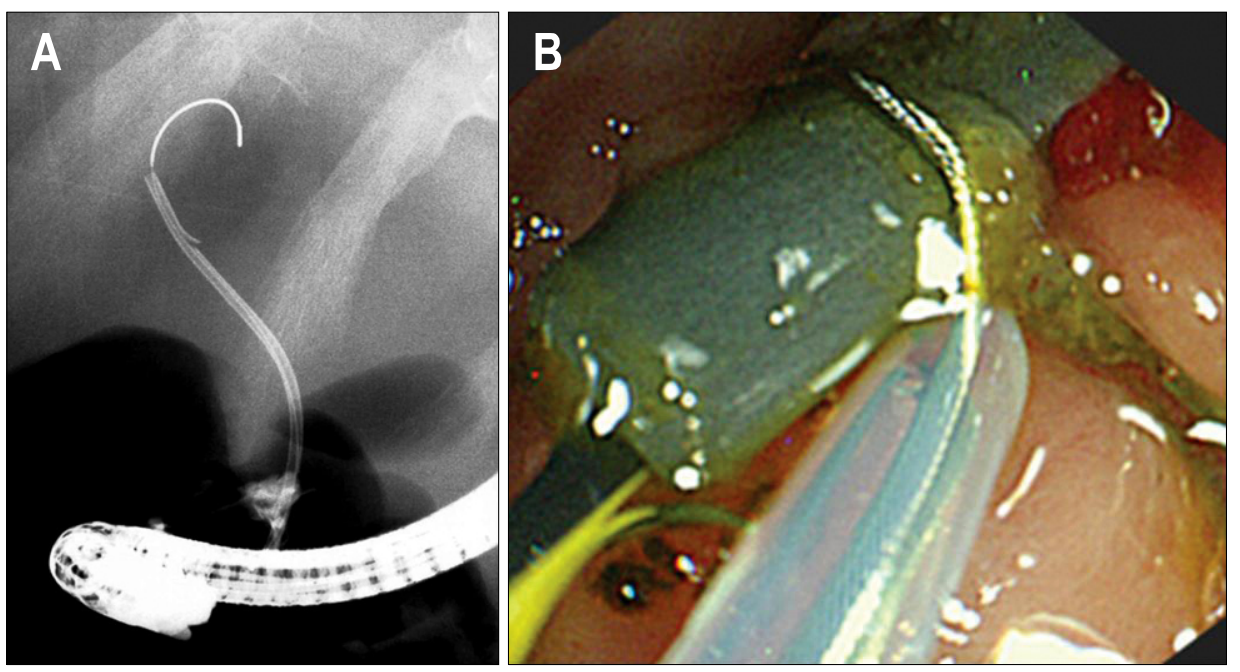

Fig. 3. Guide wire-assisted stent exchange. (A) A 0.035-inch guide wire was inserted into the bile duct through an occluded stent using an ERCP catheter. (B) The occluded stent was removed using a snare with the guidewire in place, through the biopsy channel of the duodenoscope. 
Table 2. Overview in the Reported Cases with EUS-Guided Choledochoduodenostomy

\begin{tabular}{|c|c|c|c|c|c|c|c|}
\hline Authors & Year & $\begin{array}{l}\text { No. of } \\
\text { cases }\end{array}$ & Device for puncture & $\begin{array}{l}\text { Technical } \\
\text { success (\%) }\end{array}$ & $\begin{array}{l}\text { Treatment } \\
\text { success (\%) }\end{array}$ & $\begin{array}{l}\text { Initial stent } \\
\text { (No. of cases) }\end{array}$ & $\begin{array}{l}\text { Early complication } \\
\text { (No. of cases) }\end{array}$ \\
\hline Giovanini et al. & 2001 & 1 & NK (1) & 1/1 (100) & 1/1 (100) & 10F PS & None \\
\hline Brumester et al. & 2003 & 2 & 19G FT (2) & $1 / 2(50)$ & 1/1 (100) & 8.5F PS & Bile peritonitis (1) \\
\hline Puspok et al. & 2005 & 5 & NK (5) & $4 / 5(80)$ & 4/4 (100) & 7-10F PS & None \\
\hline Kahaleh et al. & 2006 & 1 & 19G FN (1) & $1 / 1 \quad(100)$ & $1 / 1(100)$ & $10 \mathrm{~mm}$ MS & Pneumoperitoneum (1) \\
\hline Yamao et al. & $2006,06,08^{*}$ & 5 & NK (5) & $5 / 5(100)$ & $5 / 5(100)$ & 7-8.5F PS & Pneumoperitoneum (1) \\
\hline Ang et al. & 2007 & 2 & NK (2) & $2 / 2(100)$ & $2 / 2(100)$ & 7F PS & Pneumoperitoneum (1) \\
\hline Fujita et al. & 2007 & 1 & 19G FN (1) & $1 / 1 \quad(100)$ & 1/1 (100) & 7F PS & None \\
\hline Tarantino et al. & 2008 & 4 & $\begin{array}{l}\text { 19G, 22G } \\
\text { FN/NK (4) }\end{array}$ & $4 / 4(100)$ & $4 / 4(100)$ & $\mathrm{PS}^{\dagger}$ & None \\
\hline Itoi et al. & 2008 & 4 & NK (2), 19G FN (2) & 4/4 (100) & 4/4 (100) & 7F PS (3), NBD (1) & Bile peritonitis (1) \\
\hline Hanada et al. & 2009 & 4 & 19G FN (4) & 4/4 (100) & 4/4 (100) & 6-7F PS & None \\
\hline Park et al. & 2009 & 4 & 19G FN/NK (4) & 4/4 (100) & 4/4 (100) & $10 \mathrm{~mm}$ CMS & None \\
\hline Total & & 33 & & $\begin{array}{l}31 / 33 \\
(94)\end{array}$ & $31 / 31(100)$ & & $5 / 33(15)$ \\
\hline
\end{tabular}

NK, needle knife; FT, fistolotome; FN, fine needle; PS, plastic stent; MS, metal stent; NBD, nasobiliary drainage; CMS, covered metal stent.

*Excluding the overlapping cases; ${ }^{\dagger}$ Stent diameter is not described.

serted including a metal stent in 5 patients. The rate of treatment success was $31 / 31(100 \%)$ among the patients with successful EUS-CDS access.

The advantage of the EUS-CDS technique is that the puncture site is very close to the extrahepatic bile duct and away from the obstructing tumor. ${ }^{21}$ There are no large intervening blood vessels between the duodenal wall and the extrahepatic bile duct. The echoendoscope is stable in this position and the direction of the puncture is upwards towards the hepatic hilum. To prevent the dislocation of the guide wire and the dilator, an appropriate puncture site should be selected aiming at the extrahepatic bile duct between the upper margin of the pancreas and hepatic hilum. The one-step method with direct puncture of the extrahepatic bile duct may reduce the risk of guide wire dislocation while the instruments are exchanged. Comparatively high rates of complications (15\%) have been reported, including 2 cases of small focal bile peritonitis ${ }^{5,22}$ and 3 cases of pneumoperitoneum. . $^{13,15,21}$

We have previously reported long-term follow-up data on stent patency in patients who underwent EUS-CDS. The average patency of the stents was 211.8 days, ${ }^{21}$ which is significantly longer than the patency duration of trans-papillary plastic biliary stents. We speculate that EUS-CDS can prevent stent clogging and tumor ingrowth and/or overgrowth because it creates a fistula away from the obstructing tumor. The comparatively long patency of EUS-CDS achieved in our patients appears to be superior to that of trans-papillary plastic stents and uncovered metallic stents, and inferior to that of covered metallic stents in patients with lower biliary obstruction. Additionally, the stent used in EUS-CDS is significantly cheaper and can be exchanged unlike metallic stents. Recently, Park et al. $^{25}$ reported 5 cases of EUS-BD with one-step placement of a fully covered self-expandable metal stent. Although the follow-up periods were short (median, 6 months; range, 2-7 months), there was only one re-intervention necessitated by stent migration. So a longer stent patency using a fully covered metal stent can be expected.

\section{EUS-guided hepaticogastrostomy}

EUS-guided hepaticogastrostomy was first reported by Burmester et $a .^{5}$ in 2003. The technique is also basically similar to EUS-guided drainage of pancreatic pseudocysts.

\section{1) Technique for EUS-guided hepaticogastrostomy}

(1) A curved linear echoendoscope in a short position can display the intrahepatic bile ducts from the upper body of the stomach. The needle should be directed towards the hepatic hilum.

(2) A dilated peripheral branch of the left intra-hepatic system that is closest to the EUS transducer is accessed transgastrically using a 19- or 22-gauge needle or a needle knife.

(3) After removal of the needle stylet, bile is aspirated and contrast is injected to visualize the ducts under fluoroscopy (Fig. 4A).

(4) A 0.035 or 0.021 inch guide wire is then passed via the FNA needle into the left intra-hepatic system. The wire should be positioned deep into the peripheral intra- 

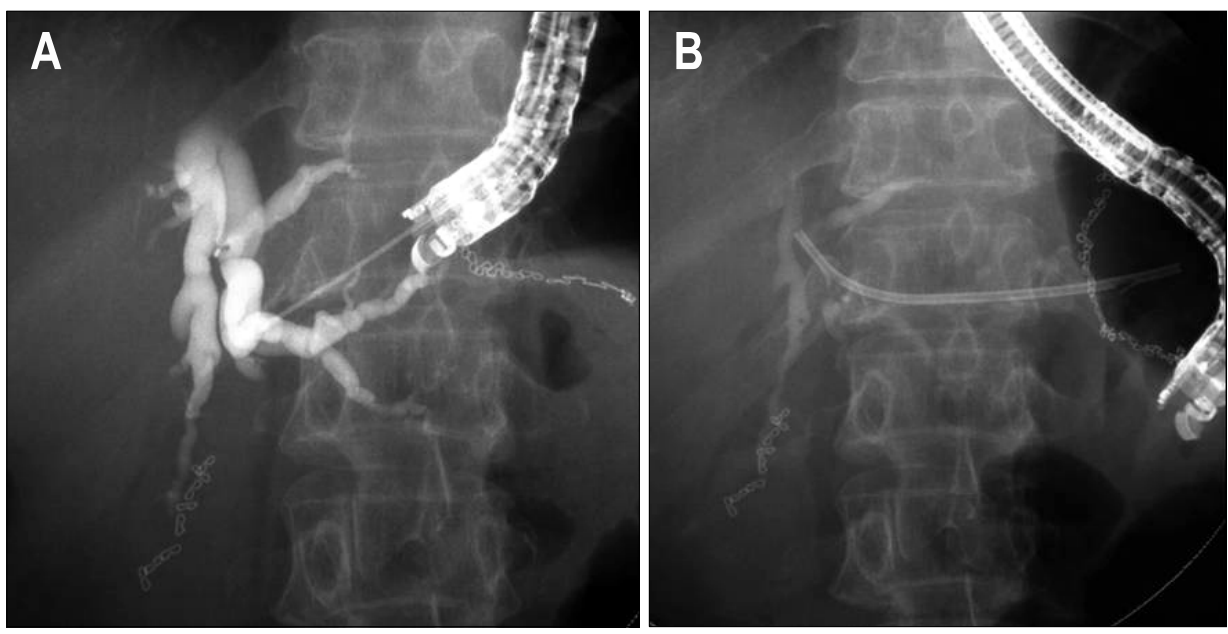

Fig. 4. Endoscopic ultrasonography-guided hepatogastrostomy. (A) A dilated peripheral branch of the left intra-hepatic system that was accessed transgastrically using a 22-gauge needle. (B) A 7 Fr biliary plastic stent was inserted though the hepaticogastrosotomy site into intrahepatic bile ducts.

Table 3. Overview in the Reported Cases with EUS-Guided Hepatogastrostomy

\begin{tabular}{|c|c|c|c|c|c|c|c|}
\hline Authors & Year & $\begin{array}{l}\text { No. of } \\
\text { cases }\end{array}$ & $\begin{array}{l}\text { Device for } \\
\text { puncture }\end{array}$ & $\begin{array}{c}\text { Technical } \\
\text { success (\%) }\end{array}$ & $\begin{array}{l}\text { Treatment } \\
\text { success (\%) }\end{array}$ & Initial stent & $\begin{array}{c}\text { Early complication } \\
\text { (No. of cases) }\end{array}$ \\
\hline Brumester et al. & 2003 & 1 & 19G FT & 1/1 (100) & $1 / 1(100)$ & 8.5F PS & None \\
\hline Kahaleh et al. & 2006 & 2 & 19G, 22g FN & $2 / 2(100)$ & $2 / 2(100)$ & 10F PS & None \\
\hline Artifon et al. & 2007 & 1 & $19 \mathrm{G} F N$ & 1/1 (100) & $1 / 1 \quad(100)$ & $10 \mathrm{~mm}$ CMS & None \\
\hline Bories et al. & 2007 & 11 & 19G, $22 \mathrm{FN} / \mathrm{CT}$ & $10 / 11(91)$ & $10 / 10(100)$ & 7F PS, $10 \mathrm{~mm} \mathrm{CMS}$ & PS $(1)^{*}$, CMS $(3)^{\dagger}$ \\
\hline Will et al. & 2007 & 4 & 19G FN & 4/4 (100) & $3 / 4(75)$ & $10 \mathrm{~mm} \mathrm{MS}, \mathrm{CMS}$ & Cholangitis (1) \\
\hline Park et al. & 2009 & 9 & 19G FN/NK & 9/9 (100) & 9/9 (100) & $10 \mathrm{~mm} \mathrm{CMS}$ & None \\
\hline Total & & 28 & & $27 / 28(96)$ & $26 / 27(96)$ & & $5 / 28(18)$ \\
\hline
\end{tabular}

FT, fistolotome; FN, fine needle; CT, cystotome; NK, needle knife; PS, plastic stent; CMS, covered metal stent; MS, metal stent. *Ileus; ${ }^{\dagger}$ Biloma, stent migration, and cholangitis in each case.

hepatic bile ducts, or should pass into the duodenum across the biliary stricture.

(5) The trans-mural tract between the stomach and the left intra-hepatic system can be dilated using either an ERCP cannula, cystotome (6 Fr or $8.5 \mathrm{Fr}$ ), a $6 \mathrm{Fr}$ bougie or a 4 or $6 \mathrm{~mm}$ dilating balloon, if necessary.

(6) A 5-Fr to 10-Fr biliary plastic stent, or a covered or uncovered MS is then inserted though the hepaticogastrostomy site into intrahepatic bile ducts (Fig. 4B).

\section{2) Review of published literature on EUS-guided hepaticogastrostomy (Table 3)}

To date, 28 patients with EUS-guided hepaticogastrostomy have been reported in six studies., ${ }^{5,13,17-19,25} 19$ gauze or 22 gauze fine needles or fine needles followed by needle knife or cystotome were used for puncturing intrahepatic bile ducts in all of the patients. The procedure was successful in all but one case $(27 / 28,96 \%)$. Various types of stents, including plastic stents, uncovered MS, and covered MS were used for the drainage. Once the stents were placed, all but one patient $(26 / 27,96 \%)$ had successful resolution of obstructive jaundice. The rate of procedure-related early complications was $14 \%$ without mortality: 1 case of ileus probably due to the use of morphine during anesthesia, 1 case of bilioma, and 2 cases of cholangitis. ${ }^{17}$ Stent migration has been reported as a late complication in one case. ${ }^{25}$

Kahaleh et al..$^{13}$ described that the advantages of EUS-guided hepaticogastrostomy over percutaneous transhepatic drainage included puncture of the biliary tree with real-time US when using color-Doppler information to limit the possibility of vascular injury, the lack of ascites in the interventional field when present in the peritoneum, and the lack of an external drain. And based on their experience, they also pointed out the extrahepatic approach has a greater chance of complication than the intrahepatic approach. Itoi $e t$ al. ${ }^{22}$ reported the limitations of this technique as follows, (i) non-apposed gastric wall and the left liver lobe, with a certain displacement between the puncture site of the gastric wall and intrahepatic bile duct, resulting in possibility of procedure failure. (ii) risk of mediastinitis with a transesophageal approach, (iii) difficulty of puncture in case of liver cirrhosis, (iv) risk of injuring the portal vein and (v) neces- 
sitating the use of small-caliber stents or MS with a small-diameter delivery device.

\section{CONCLUSION}

We conclude that, (i) Rendezvous technique is safer compared to the direct access techniques. The former may be better than the direct access techniques in patients with significant ascites or in pre-operative cases. However, it is complicated and requires a longer time compared to the other EUS-BD, (ii) transduodenal approach is easier to access extrahepatic bile ducts, and it is easier to dilate the fistula compared with the transgastric approach, (iii) because the transgastric approach needs a larger stent diameter to prevent stent occlusion by food, metal stents may be more appropriate for the transgastric approach.

As more experience is gained, we have to determine which of the following are more effective than their alternatives: (i) transduodenal approach vs transgastric approach, (ii) direct access vs rendezvous technique, (iii) fistulotome vs fine needle for bile duct puncture, (iv) tapered biliary dilators vs balloon dilation, (v) plastic stent vs (covered) metal stent, (vi) straight stent vs pig tail stent, (vii) 8.5 Fr stent vs more or less size stent. Large prospective studies as well as controlled studies mentioned above and comparative trials between EUS-BD versus PTBD, rendezvous technique versus direct access technique (EUS-CDS and EUS-HGS), and EBD versus EUS-BD are needed in near future.

\section{REFERENCES}

1. Vilmann P, Jacobsen GK, Henriksen FW, Hancke S. Endoscopic ultrasonography with guided fine needle aspiration biopsy in pancreatic disease. Gastrointest Endosc 1992;38:172-173.

2. Bhutani MS. Endoscopic ultrasound guided fine needle aspiration of pancreas. In: Bhutani MS, ed. Interventional Endoscopic Ultrasonography. Amsterdam: Harwood Academic, 1999:65-72.

3. Wiersema MJ, Sandusky D, Carr R, Wiersema LM, Erdel WC, Frederick PK. Endosonography-guided cholangiopancreatography. Gastrointest Endosc 1996;43:102-106.

4. Giovannini M, Moutardier V, Pesenti C, Bories E, Lelong B, Delpero JR. Endoscopic ultrasound-guided bilioduodenal anastomosis: a new technique for biliary drainage. Endoscopy 2001;33:898-900.

5. Burmester E, Niehaus J, Leineweber $T$, Huetteroth $T$. EUS-cholangio-drainage of the bile duct: report of 4 cases. Gastrointest Endosc 2003;57:246-251.

6. Mallery S, Matlock J, Freeman ML. EUS-guided rendezvous drainage of obstructed biliary and pancreatic ducts: report of 6 cases. Gastrointest Endosc 2004;59:100-107.
7. Kahaleh M, Yoshida C, Kane L, Yeaton P. Interventional EUS cholangiography: a report of five cases. Gastrointest Endosc 2004;60:138-142.

8. Lai R, Freeman ML. Endoscopic ultrasound-guided bile duct access for rendezvous ERCP drainage in the setting of intradiverticular papilla. Endoscopy 2005;37:487-489.

9. Kahaleh M, Wang P, Shami VM, Tokar J, Yeaton P. EUS-guided transhepatic cholangiography: report of 6 cases. Gastrointest Endosc 2005;61:307-313.

10. Puspok A, Lomoschitz F, Dejaco C, Hejna M, Sautner T, Gangl A. Endoscopic ultrasound guided therapy of benign and malignant biliary obstruction: a case series. Am J Gastroenterol 2005;100:1743-1747.

11. Yamao K, Sawaki A, Takahashi K, Imaoka H, Ashida R, Mizuno N. EUS-guided choledochoduodenostomy for palliative biliary drainage in case of papillary obstruction: report of 2 cases. Gastrointest Endosc 2006;64:663-667.

12. Yamao K, Mizuno N, Takahashi K, et al. A case of duodenoscopic ultrasound guided transduodenal biliary drainage in a case of carcinoma of papilla of Vater. Suizo 2006; 21:353-357.

13. Kahaleh M, Hernandez AJ, Tokar J, Adams RB, Shami VM, Yeaton P. Interventional EUS-guided cholangiography: evaluation of a technique in evolution. Gastrointest Endosc 2006;64:52-59.

14. Will U, Thieme A, Fueldner F, Gerlach R, Wanzar I, Meyer F. Treatment of biliary obstruction in selected patients by endoscopic ultrasonography (EUS)-guided transluminal biliary drainage. Endoscopy 2007;39:292-295.

15. Ang TL, Teo EK, Fock KM. EUS-guided transduodenal biliary drainage in unresectable pancreatic cancer with obstructive jaundice. JOP 2007;8:438-443.

16. Fujita N, Noda Y, Kobayashi G, et al. Histological changes at an endosonography-guided biliary drainage site: a case report. World J Gastroenterol 2007;13:5512-5515.

17. Bories E, Pesenti C, Caillol F, Lopes C, Giovannini M. Transgastric endoscopic ultrasonography-guided biliary drainage: results of a pilot study. Endoscopy 2007;39:287291.

18. Will U, Fueldner F, Thieme AK, et al. Transgastric pancreatography and EUS-guided drainage of the pancreatic duct. J Hepatobiliary Pancreat Surg 2007;14:377-382.

19. Artifon EL, Chaves DM, Ishioka S, Souza TF, Matuguma SE, Sakai P. Echoguided hepatico-gastrostomy: a case report. Clinics (Sao Paulo) 2007;62:799-802.

20. Tarantino I, Barresi L, Repici A, Traina M. EUS-guided biliary drainage: a case series. Endoscopy 2008;40:336-339.

21. Yamao K, Bhatia V, Mizuno N, et al. EUS-guided choledochoduodenostomy for palliative biliary drainage in patients with malignant biliary obstruction: results of long-term follow-up. Endoscopy 2008;40:340-342.

22. Itoi $\mathrm{T}$, Sofuni A, Itokawa $\mathrm{F}$, et al. Endoscopic ultrasonography-guided biliary drainage. J Hepatobiliary Pancreat Surg. Forthcoming 2010. DOI: 10.1007/s00534009-0196-1.

23. Kim YS, Gupta K, Mallery S, Li R, Kinney T, Freeman ML. Endoscopic ultrasound rendezvous for bile duct access using a transduodenal approach: cumulative experience at a single center. A case series. Endoscopy 2010;42:496-502.

24. Hanada K, Iiboshi T, Ishii Y. Endoscopic ultrasound-guided choledochoduodenostomy for palliative biliary drainage in 
cases with inoperable pancreas head carcinoma. Dig Endosc 2009;21 Suppl 1:S75-S78.

25. Park do H, Koo JE, Oh J, et al. EUS-guided biliary drainage with one-step placement of a fully covered metal stent for malignant biliary obstruction: a prospective feasibility study. Am J Gastroenterol 2009;104:2168-2174.

26. Maranki J, Hernandez AJ, Arslan B, et al. Interventional endoscopic ultrasound-guided cholangiography: long-term experience of an emerging alternative to percutaneous transhepatic cholangiography. Endoscopy 2009;41:532-538.

27. Hara K, Yamao K, Mizuno N, Sawaki A, Takagi T, Bhatia V. Endoscopic ultrasound-guided choledochoduodenostomy. Dig Endosc 2010;22:147-150. 